Article

\title{
Shear Rate-Dependent Rheological Properties of Mine Tailings: Determination of Dynamic and Static Yield Stresses
}

\author{
Sueng-Won Jeong \\ Korea Institute of Geoscience and Mineral Resources, Daejeon 34132, Korea; swjeong@kigam.re.kr
}

Received: 9 August 2019; Accepted: 5 November 2019; Published: 7 November 2019

\begin{abstract}
In this paper, shear rate-dependent rheological properties of mine tailings taken from abandoned mine deposits prone to mass movements are examined using a commercial ball-measuring rheological system. The yield stresses (i.e., dynamic and static yield stresses) and viscosity of sand-rich materials are examined by the shear rate-controlled flow curve and time-dependent stress growth methods. Before yielding, the shear stress reaches a peak value (i.e., yield stress) observed for all flow curves. In the steady-state condition, the materials have a minimum shear stress (i.e., dynamic yield stress). The static yield stress can be determined under a constant applied shear rate with different initial values ranging from $10^{-4}$ to $10^{-1} \mathrm{~s}^{-1}$. As a result, the Bingham yield stress and viscosity can be used as a first approximation for estimating the debris flow mobility of post-failure materials. However, the Bingham yield stress is competitive with the static yield stress measured from stress growth methods. Upon comparison of the dynamic and static yield stresses, the static yield stress is approximately 35-45 times greater than the dynamic yield stress, and may be strongly related to microstructural changes (i.e., thixotropy). In this context, special attention must be paid to the determination of yield stresses in debris flow mitigation programs.
\end{abstract}

Keywords: dynamic yield stress; static yield stress; initial shear rate; mine tailings; debris flow

\section{Introduction}

The yield stress is a special property associated with non-Newtonian fluids, such as clay suspensions, concrete cements, crude oil, foams, food, paints, pastes, and polymers [1-6]. In general, the yield stress is defined as the shear stress at the point where the applied stress exceeds the critical shear rate; in this case, the material starts to flow. Materials may deform elastically due to structural changes below the yield stress, but they may deform greatly and flow like liquids above the yield stress. There are numerous methods that can be employed to determine the yield stress of non-Newtonian fluids: model fitting, a slump test, an inclined plane test, a stress ramp test, a stress growth test, oscillation amplitude sweep, and creep tests. However, the yield stress is strongly dependent on the test conditions and techniques employed [7,8]. In addition, many non-Newtonian fluids are thixotropic $[9,10]$. Structural changes with time are unavoidable during shear. Time-dependent rheological characteristics make it difficult to find a robust method for determining the true yield stress [11]. This subject is still under debate in cement and concrete research (such as building materials) and disaster-prevention measures (such as debris flow analysis for estimating future catastrophic hazards).

The dynamic and static yield stresses can be determined by equilibrium flow curves and stress growth methods. The dynamic yield stress is the minimum shear stress in the flow curve with a steady-state flow condition, while the static yield stress is the peak shear stress measured with a constant shearing time [12]. It is also well-known that the dynamic yield stress is associated with 
flow stopping, but the static yield stress is associated with flow starting [13]. According to previous studies [6], the dynamic and static yield stresses are related to the state before and after microstructural changes in materials. In addition, the conception of the time depending on the value of the yield stress has been pointed out by numerous studies [14-16]. As a result, it is expected that the value of dynamic yield stress is much lower than that of static yield stress with respect to the structural states. It is well-known that the yield stress is related to the structural change, that is, thixotropy.

Rheological properties are essential in the fluid industry and natural disaster-related sciences. The rheological properties are examined for various materials, such as clay suspensions, muds, sand-rich materials, and reconstituted pyroclastic debris flows $[13,17-20]$. Water is typically a viscous liquid, while particle-bearing liquids typically behave as non-Newtonian fluids, indicating more complex rheological characteristics. Few studies have focused on the geotechnical and rheological properties of post-failure materials in mass movements, which can result in rapid complex fluid-like behavior as a kind of soil liquefaction. In the field of debris flows, a multiphase process in large particle-bearing debris flows is of paramount importance [21] because they are very dense and exhibit strong interactions between particles in the interstitial fluid. Rheological tests are often considered large particle-laden flows, e.g., the mean grain size of materials tested in rheometers has often been a typical sand with particle sizes from 0.075 to $2 \mathrm{~mm}$ in diameter. However, the change in rheological properties is significant when the solid fraction is slightly changed [13]. The disposal of mine tailings and waste rock materials involving sand- and gravel-size particles in open pits is a problem that needs to be managed. Severe erosion and mass movements in abandoned mine deposits can result in physicochemical contamination at and near the mine deposits [22]. In this case, the determination of flow properties is crucial for debris flow rheology [19] because the runout distances and speeds of debris flows are mainly estimated by yield stress and viscosity [23]. When estimating the runout distance of debris flows in coarse-grained sediments, the rheological characteristics are the decisive criteria for mitigating and managing future debris flow events in mountainous areas. However, the determination of dynamic and static yield stresses in debris flows is still poorly studied.

In this study, the dynamic and static yield stresses of sand-rich materials taken from abandoned mine deposits are studied. First, the flow behaviors of the sand-rich materials are examined as a function of the shear rate (i.e., the flow curve) at the same solid volume concentration. Second, the rheological properties, i.e., yield stresses and viscosity, are determined using model fitting, including Bingham, Herschel-Bulkley, bilinear, modified Bingham, and power law models. The initial shear rate-dependent shear stress is examined. Third, under a constant applied shear rate, the stress build-up with time is monitored. The differences in dynamic and static yield stresses as a function of shear rate are highlighted. Finally, the shear strengths, including the undrained shear strength measured from fall cone tests, the Bingham yield stress, and the static yield stress in modeling the debris flow, are compared. Creep and recovery tests are not taken into account. It should also be noted that pre-shearing has an impact on the determination of yield stress with respect to the flocculation state in the materials. Therefore, only a limited situation can be discussed.

\section{Materials and Methods}

\subsection{Materials}

The materials tested were mine tailings taken from an abandoned mine deposit site located in Busan Metropolitan City, Republic of Korea. The grain sizes were fine to coarse, and the shapes were subangular. The main mineralogical composition was quartz, pyrophyllite, pyrite, sericite, and kaolin clay [22,24]. The on-site materials are very coarse: $30 \%$ gravel, $60-70 \%$ sand, and $5 \%$ finer sizes (clay and silt particles). The natural water content is less than $10 \%$, and the permeability $(k)$ is very high (e.g., $k \geq 2 \times 10 \mathrm{~cm} / \mathrm{s}^{-1}$ ). In the waste rock dump with a low level of vegetation, abandoned mine deposits experience severe erosion. In addition, after torrential rainfall events in the summer monsoon season, several traces of mass movements (e.g., rotational slumps, slides, and debris flows) can be found on 
natural slopes. Failed materials often flow and are deposited in a mountain stream at and near the waste rock dump. In brief, the materials can be gravelly sands; however, they are very difficult to test in conventional rheological tests because most rheometers are suitable for fine-grained sediments. To measure these materials, a series of rheometric tests was performed on the material passing through a No. 4 sieve (i.e., sand-rich materials) using a ball-penetrating torque-measured system called the "ball-measuring system (BMS)" in this study.

\subsection{Methods}

Numerous testing methods and apparatuses have been designed for determining the soil resistance of debris flow materials in the range from microscale to macroscale measuring systems (e.g., plate-plate, cone-plate, cylinder, vane, stirrer, slump, and large-scale devices). Figure 1 shows the rheometer used in this study. The commercial ball-measuring rheological system (BMS, RheolabQC, Anton Paar) consists of three balls and a container. The balls have three diameters, i.e., 10, 12, and $15 \mathrm{~mm}$, whilst the container (cup) has a diameter of $115 \mathrm{~mm}$ with a sample volume of $500 \mathrm{~cm}^{3}$. In this system, a homogenous soil sample, the mixture of soil and water, is placed into the container and the ball is immersed into the soil sample. The depth of ball penetration is the same for all tests. The distance between the ball and the bottom of the container is $20 \mathrm{~mm}$. Torques are automatically recorded when rotating the ball. The shear rate control or shear stress control mode can be applied. The measurement of shear stress and the shear rate in a ball-measuring system can be performed for 1-5 mm diameter soil samples. Similar tests for large-particle fluids using a ball-measuring system have been performed by $[19,25,26]$. The edge and slip effects are assumed to be negligible. Potential slipping and gliding problems are negligible because of the ideal spherical shape used to minimize the edge effect during shearing. The system displays a wide gap between the sensor and soil sample container. In this context, it is applicable for both fine-grained and coarse-grained sediments in debris flow materials. However, there are some limitations in performing such experiments. The normal pressure effect is not taken into account. The temperature is fixed at $20^{\circ} \mathrm{C}$ during shearing. However, it is expected that the variation in temperature is one of minor effects in the rheological behavior of sediments with large particle sizes. Two simple test methods were applied to satisfy the purpose of the study. Two types of rheological tests were performed: a flow curve test and a stress growth test. The first test was conducted to determine the dynamic yield stress (e.g., the Bingham yield stress and viscosity), and the second test was conducted to determine the static yield stress (e.g., the peak and residual shear stresses). As a result, the flow curves and stress growth methods could produce shear stress vs. shear rate and shear stress vs. shearing time relationships, respectively.

To determine the yield strength of waste rock materials, the rheological models considered are as follows:

$$
\begin{gathered}
\text { Bingham : } \tau=\tau_{c}+\mu_{h} \cdot \dot{\gamma} \\
\text { Bilinear : } \tau=\tau_{y}+\mu_{h} \cdot \dot{\gamma}^{n}+\left(\frac{\tau_{c} \cdot \dot{\gamma}}{\dot{\gamma}+\dot{\gamma}_{o}}\right) \\
\text { Modified Bingham }: \tau=\left[\mu+\tau_{c} \frac{1-\exp (-m \dot{\gamma})}{\dot{\gamma}}\right] \dot{\gamma} \\
\text { Herschel-Bulkley : } \tau=\tau_{c}+K \cdot \dot{\gamma}^{n} \\
\text { Power law }: \tau=\mu \cdot \dot{\gamma}^{n},
\end{gathered}
$$

where $\tau$ is the shear stress (Pa), $\mu$ is the viscosity (Pa.s), and $\dot{\gamma}$ is the shear rate ( $\left.\mathrm{s}^{-1}\right)$. In Equation (1), $\tau_{c}$ is the yield stress $(\mathrm{Pa})$, which is called the Bingham yield stress, and $\mu_{h}$ is the plastic viscosity (Pa.s). In Equation (2), $\tau_{y}$ is the yield stress (Pa) obtained from the bilinear model, which is similar to the yield stress obtained from the Bingham fluid; the exponent $n$ is the flow behavior index (dimensionless); and $\dot{\gamma}_{o}$ is the shear rate related to the rheological transition from a Newtonian viscosity to an ideal 
plastic viscosity. The exponent $n$ is also used in the Herschel-Bulkley and power law models to describe the flow behavior, e.g., if $n<1$, pseudoplastic (shear thinning) behavior occurs, and if $n>1$, dilatant (shear thickening) behavior occurs. Equation (3) is the modified Bingham model. It is a well-known model used to describe the transition from the pseudo-viscosity regime (elastic-dominant slope before yielding) to yielding in the flowing region. The value of $m$ is a parameter related to surface yielding in shear stress at relatively low shear rates (unit of time, s). In Equation (4), if $n=1$, it is the same as the Bingham fluid, and if $\tau_{c}=0$, it reduces to the power law model. $K$ is the consistency coefficient (Pa.s). The exponent $n$ is 0.3 for clays, 0.8 for silt-rich materials, and 0.8 for bentonite [27]. In Equation (5), if $n=1$, it is a Newtonian viscosity model.

The shear strengths measured from the BMS were compared with those obtained from fall cone tests with different solid volume concentrations. Swedish fall cones were used at 60 degrees with different cone weights, such as 10,60,100, and $400 \mathrm{~g}$. The test procedures were identical to those of [28].

(a) Ball-Measuring Rheometric System

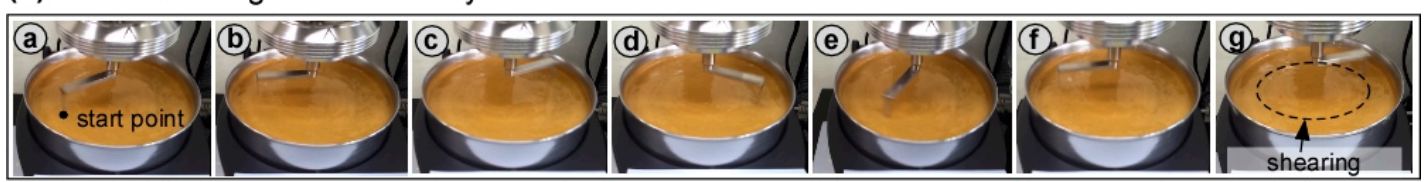

(b) Ball rotation

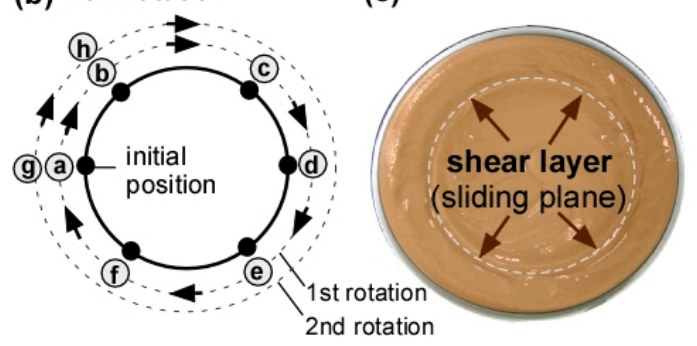

(e)

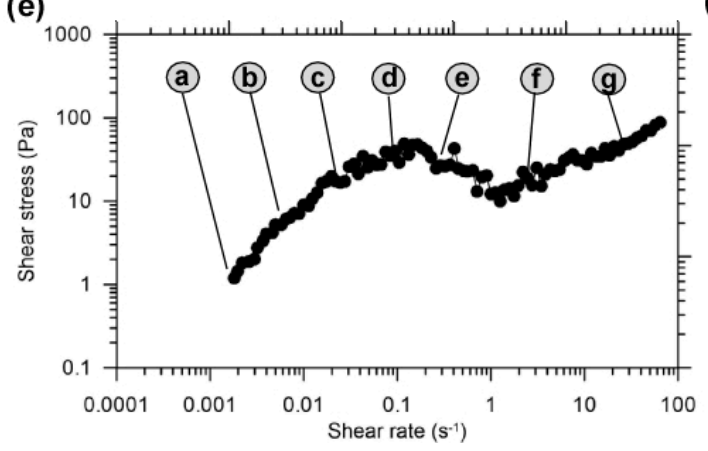

(d)

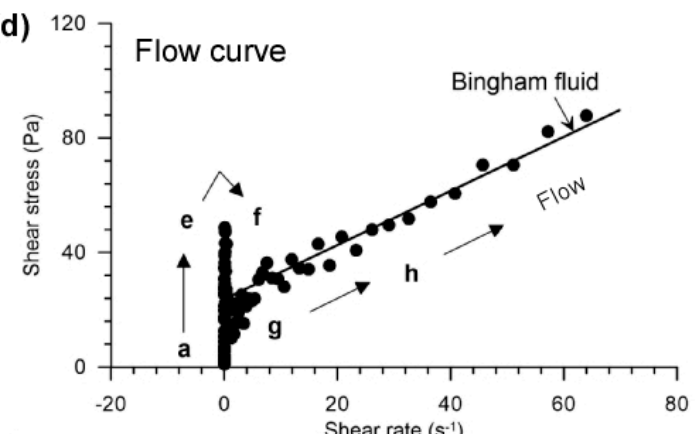

(f)

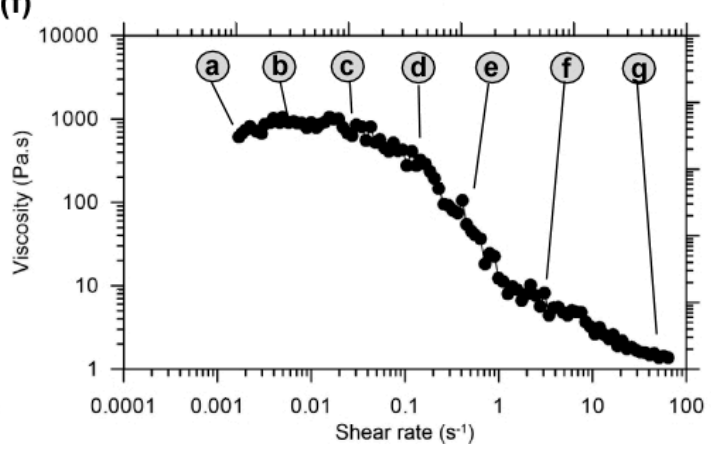

Figure 1. Ball-measuring rheometric system: (a) Test procedure, (b) schematic view of ball rotation, (c) shear layer formation (sliding plane in a steady-state condition) during shearing, (d) flow curve with Bingham fluid and ball rotation, (e) shear stress-shear rate plot, and (f) viscosity-shear rate plot. Tested from (a) to (g).

\section{Results}

\subsection{Rheological Properties of Mine Tailings: Yield Stress and Viscosity}

Figure 2 presents the flow characteristics of waste materials with initial shear rates for a water content of $34 \%$ (equivalent to a solid volume concentration of 52\%). At the same water content (or solid volume concentration), the flow behavior is very similar (Figure 2a). To examine the rheological characteristics, the controlled shear rate mode was employed with a range of $10^{-4}$ to $10^{1} \mathrm{~s}^{-1}$. In particular, five shear rates were applied as initial values from 0.0001 to $0.1 \mathrm{~s}^{-1}$. The measured 
rheological properties, that is, the yield stress and plastic viscosity, range from 17 to $21 \mathrm{~Pa}$ and 1.0 to 1.2 Pa.s, respectively. The variations in yield stress and viscosity are relatively small. They can be divided into two regimes based on a shear rate of $1 \mathrm{~s}^{-1}$ : (a) the generation of a slip surface in response to a complete rotation of a penetrated ball (after one full revolution, i.e., onset of failure stage) and (b) continuous viscous shearing (post-failure stage). An example is shown in Figure $2 b$. Compared to the flow behavior of fine-grained sediments, a large difference is shown before yielding (i.e., $\dot{\gamma}=1 \mathrm{~s}^{-1}$ ). There is a distinct peak value of shear stress at a relatively low shear rate regime (i.e., $0.4 \mathrm{~s}^{-1}$ ). After the peak value, an abrupt decrease in shear stress is observed. All processes generate a slip surface (i.e., shear banding formation in Figure 1c) in a ball-measuring system. After one full revolution of the ball, they behave as an ideal plastic fluid, such as a Bingham fluid [29]. To verify the applicability of the rheological model for obtaining flow curves, the best fit was obtained with the Bingham, bilinear, Herschel-Bulkley, modified Bingham, and power law models. As shown in Figure 2b, most of them are in good agreement with the test results after the shear rate of $1 \mathrm{~s}^{-1}$, but a large scatter is found at lower shear rates. In this context, the post-failure characteristics are limited to the flow behaviors observed after the critical deformation. The results of model fitting with respect to different initial shear rates ranging from $10^{-4}$ to $10^{-1} \mathrm{~s}^{-1}$ are summarized in Table 1 . Compared to the rheological properties of fine-grained sediments, the properties of these materials are slightly higher. According to Jeong et al. [27], the rheological compilation of clay-rich, silt-rich, and sand-rich materials shows viscosities of approximately 20,200, and $2000 \mathrm{mPa} \cdot \mathrm{s}$, respectively, in the case that the yield stress is equal to $20 \mathrm{~Pa}$. In this study, the materials tested were sand-rich materials (less cohesive). The results are in good agreement with the previous rheological compilation (especially the yield stress-viscosity relationship for the sand-rich group). Uncertainties are higher for the rheological properties measured at lower shear rates because the variations in viscosity at low shear rates (less than $1 \mathrm{~s}^{-1}$ ) are significant. In an elastic regime, the structure begins to break down, is subjected to shear localization, and creates partial shear-induced particle migration in the flow curves when the shear strain approaches the critical shear strain [6]. In the transition from the solid-like to liquid-like regime, there is a critical deformation. The shear localization and shear banding (stick-slip behavior) are dependent on increasing the apparent shear rate [30]. According to [31], shear banding instability can be divided into three regions, e.g., homogeneous, wall slip, and bulk shear banding. In this regard, the term "shear layer" in Figure 1 is more appropriate and could describe the area where the shear stresses (shear forces) are applied to the suspension structure. At a relatively high shear rate, the Bingham rheological concept is well-matched. The viscosity before $1 \mathrm{~s}^{-1}$ can be considered pseudo-Newtonian viscosity [27], which is defined as the slope of the line fit between the origin ( 0 value in flow curves) and the maximum value reached before the critical shear rates (in this case, $1 \mathrm{~s}^{-1}$ ). As a result, the lower the initial shear rates are, the higher the slopes (Table 1). This result may occur because the pseudo-Newtonian viscosity (i.e., the slope determined before yielding) gradually approaches the y-axis as the initial shear rates decrease.
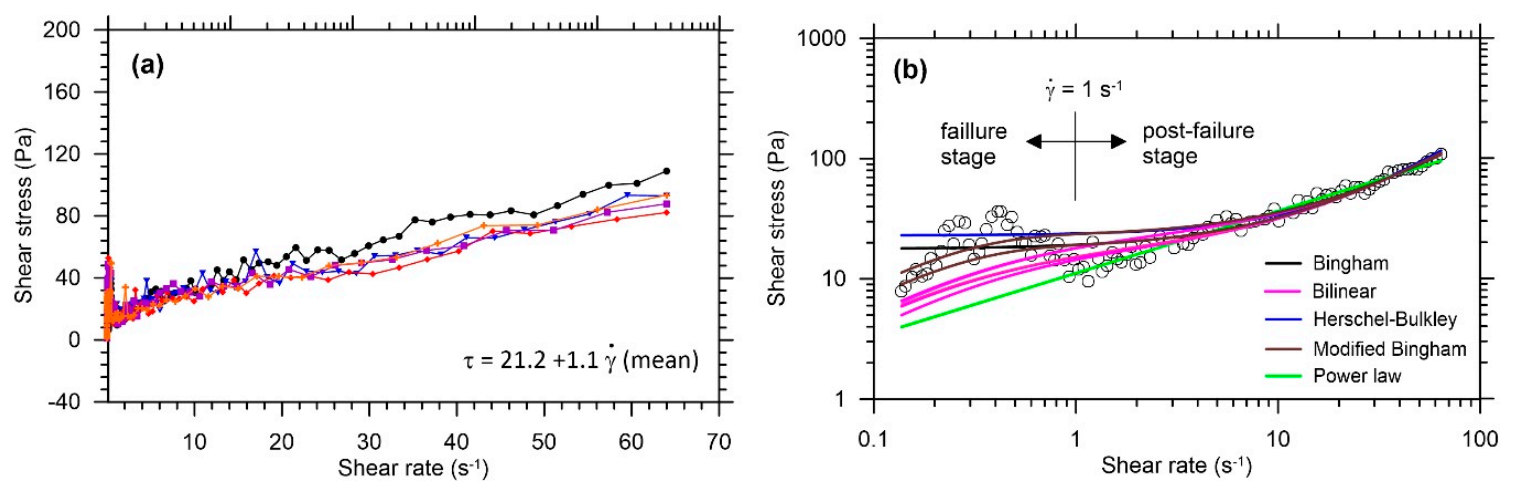

Figure 2. Flow curves and model fitting: (a) Shear stress and shear rate relationships with the mean value of flow equation; (b) model fitting with Bingham, Bilinear, Herschel-Bulkley, Modified Bingham, and Power law. 
Table 1. Rheological properties obtained from different rheological models.

\begin{tabular}{cccccccccccc}
\hline & \multicolumn{3}{c}{ Bingham } & \multicolumn{3}{c}{ Bilinear } & Modified Bingham & \multicolumn{2}{c}{ Herschel-Bulkley } & \multicolumn{2}{c}{ Power Law } \\
\hline$\dot{\gamma}$ & $\boldsymbol{\tau}_{\boldsymbol{c}}$ & $\eta_{\boldsymbol{h}}$ & $\dot{\gamma}_{\boldsymbol{o}}$ & $\boldsymbol{c}$ & $\boldsymbol{\eta}_{\boldsymbol{p} \boldsymbol{N}}$ & $\boldsymbol{m}$ & $\boldsymbol{\tau}_{\boldsymbol{c}-\boldsymbol{H B}}$ & $\boldsymbol{K}$ - $\boldsymbol{H B}$ & $\boldsymbol{n} \boldsymbol{-}_{\boldsymbol{H} \boldsymbol{B}}$ & $\boldsymbol{K}$ & $\boldsymbol{n}$ \\
\hline 0.1 & 22.39 & 1.34 & 0.47 & 10.43 & 49.4 & 10.43 & 23.0 & 0.83 & 1.14 & 11.04 & 0.52 \\
0.01 & 19.75 & 1.46 & 0.08 & 1.52 & 257.05 & 1.52 & 18.0 & 0.69 & 1.13 & 13.01 & 0.42 \\
0.001 & 15.31 & 1.10 & 0.04 & 0.61 & 384.21 & 0.61 & 15.0 & 1.96 & 0.84 & 10.88 & 0.45 \\
0.0001 & 17.02 & 1.09 & 0.03 & 0.43 & 674.49 & 0.43 & 12.0 & 1.78 & 0.96 & 11.50 & 0.45 \\
0.00001 & 15.33 & 1.13 & 0.01 & 0.14 & 1703.47 & 0.14 & 12.0 & 1.90 & 0.91 & 8.98 & 0.53 \\
\hline
\end{tabular}

Note: $\dot{\gamma}_{o}$ and c are bilinear constants; $\eta_{p N}=$ pseudo-Newtonian viscosity obtained from the Bilinear model; $m=$ model constant, $\tau_{c-H B}=$ Herschel-Bulkley yield stress; $n$ - $H B=$ flow behavior index in the Herschel-Bulkley model; $K$ and $n=$ flow behavior indices in the Power law model.

\subsection{Shear Rate-Dependent Flow Behavior: Dynamic and Static Yield Stresses}

A series of ball-measuring rheometric tests was performed to examine the shear rate dependency of rheological behavior. Two tests were considered: (a) flow curve tests with the initial shear rate gradually increasing from $10^{-5}, 10^{-4}, 10^{-3}$, and $10^{-2}$ to $10^{-1} \mathrm{~s}^{-1}$, and (b) stress growth tests at a constant shear rate with shearing time.

\subsubsection{Flow Curve Test: Initial Shear Rate Dependency}

The shear rate dependency of shear stress was examined using different initial shear rates. Figure 3 presents the shear stress-shear rate and viscosity-shear rate relationships. Five initial shear rates, consisting of $10^{-5}, 10^{-4}, 10^{-3}, 10^{-2}$, and $10^{-1} \mathrm{~s}^{-1}$, were applied to measure the flow behavior. The difference in flow curves is much clearer using the plot of logarithmic shear stress and logarithmic shear rate (Figure 3a). The measurement of shear stress depends on the applied initial shear rate. For example, the first measurement of shear stress is equal to $1 \mathrm{~Pa}$ at approximately $10^{-3} \mathrm{~s}^{-1}$ when an initial shear rate of $10^{-5} \mathrm{~s}^{-1}$ is applied. Delayed detection may be removed when the initial shear rate is increased (for example, initial shear rate of $10^{-1} \mathrm{~s}^{-1}$ ). Interestingly, as shown in Figure $3 \mathrm{~b}$, a pseudo-plateau regime is clearly shown when the initial shear rate applied is increased. As shown in Figure 2, after $1 \mathrm{~s}^{-1}$, the materials behave as ideal plastic fluids. In this case, the flow behavior of sand-rich materials can be governed by the Bingham constitutive law with a yield stress and plastic viscosity.
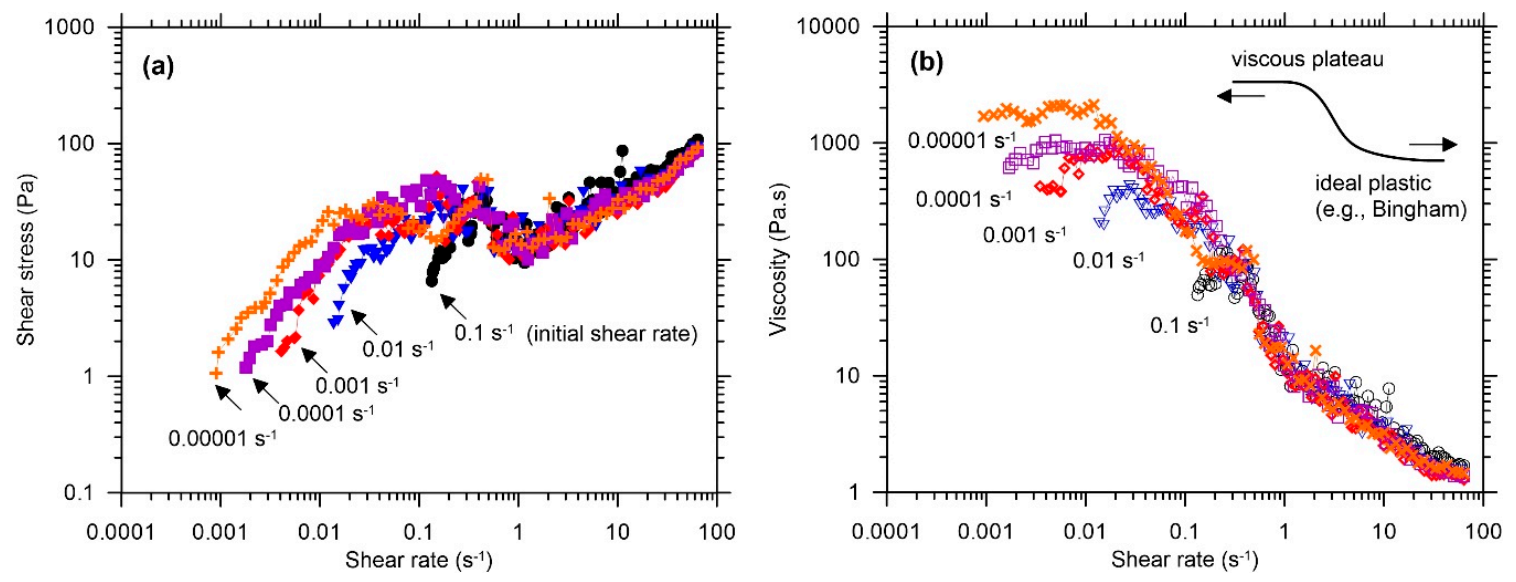

Figure 3. Shear rate dependency of rheological behavior at relatively low shear rates: (a) Shear stress-shear rate relationship and (b) viscosity-shear rate relationship

\subsubsection{Stress Growth Test: Time Dependency}

Flow-like sediments are well-known as time-dependent materials (i.e., thixotropic materials). The time dependency of the rheological behavior of waste materials at a constant shear rate was 
examined. The applied shear rates ranged from 0.001 to $1 \mathrm{~s}^{-1}$. The shear rate was continuously applied, and the torques were measured for $350 \mathrm{~s}$, except at $0.5 \mathrm{~s}^{-1}$. Most rheological tests for coarse-grained sediments are performed for relatively short periods of time, such as less than $1 \mathrm{~min}$. If the shear rate is less than $10^{-3} \mathrm{~s}^{-1}$, the test is difficult to carry out with a time constraint. Figure 4 shows the test results of the stress growth method: shear stress with time and viscosity with time. There is significant fluctuation during shearing. This large scatter (fluctuation) is observed for each flow curve. This feature may be due to interactions between large particles. The scatter may be minimized when the fine content is increased. In Figure 4a, the flow behavior is quite different when different continuous shear rates are applied at constant values during shearing. Typically, two types of shear behavior can be found for a given range of shearing times: strain hardening and strain softening behavior. The first type has a peak value (i.e., the yield stress) in shear stress with time, and the second type has a peak and a steady-state value. The latter is very similar to the residual shear stress in soil mechanics. It can be defined as the minimum shear resistance of the materials along the previously existing slip surface. Strain hardening is dominant for relatively low initial shear rates (i.e., shear rates of $10^{-3}$ and $10^{-2} \mathrm{~s}^{-1}$ ), but strain softening is dominant for relatively high initial shear rates (i.e., shear rates of $10^{-1}$ and $1 \mathrm{~s}^{-1}$ ). The transitional behavior occurs between $10^{-2}$ and $10^{-1} \mathrm{~s}^{-1}$. The shear stress fluctuation (vertical variation in shear stress for a given time) is large. This result may occur because of particle-particle interaction via the nonslip boundary system, resulting in collisions and fragmentation in coarse-grained sediments. The viscosity is also very sensitive to the shearing time (Figure $4 \mathrm{~b}$ ). At relatively low shear rates (i.e., shear rates of $10^{-3}$ and $10^{-2} \mathrm{~s}^{-1}$ ), the viscosity gradually increases with increasing shearing time; in both cases, no steady state appears for a given period of shearing time. However, when the shear rate is larger than $0.1 \mathrm{~s}^{-1}$, the viscosity reaches a peak value and gradually decreases with shearing time. After a certain amount of time, the viscosity is almost constant with time, e.g., after $250 \mathrm{~s}$ for $0.1 \mathrm{~s}^{-1}, 70 \mathrm{~s}$ for $0.5 \mathrm{~s}^{-1}$, and $60 \mathrm{~s}$ for $1 \mathrm{~s}^{-1}$.
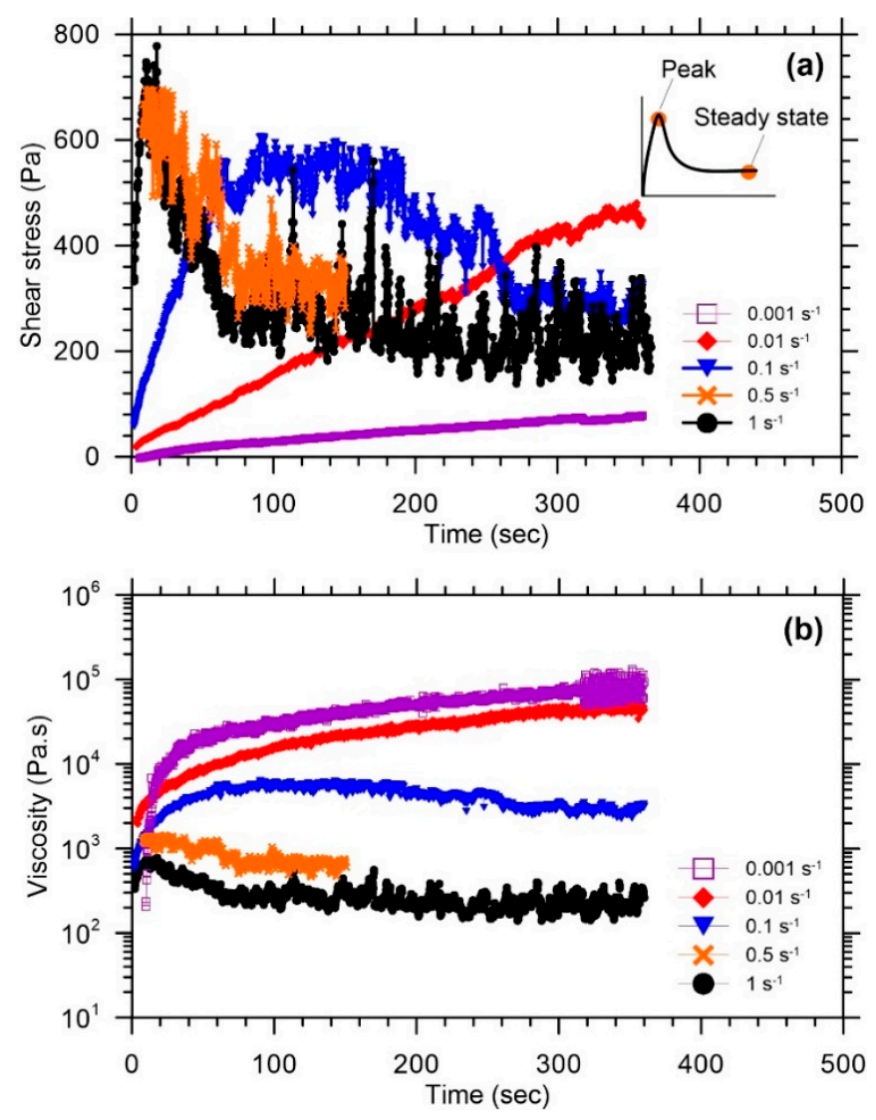

Figure 4. Stress growth test: (a) Shear stress-shearing time; (b) viscosity-shearing time. 
From the stress growth tests, the measurements of shear stress and viscosity are very sensitive to variations in the initial condition driven by shear. There are two shear stresses: a peak value and a steady-state (i.e., residual) value. The latter can be obtained at the end of the tests. As shown in Figure $5 \mathrm{a}$, the peak value of shear stress obtained from strain-hardening flow behavior gradually increases with an increasing shear rate. The residual shear stress obtained from the strain-softening flow behavior gradually decreases with increasing shear rates, except for the lowest shear rate of $0.001 \mathrm{~s}^{-1}$. It may have a very high value when a long shearing time can be applied. Interestingly, three strain-softening fluids display a similar range of residual shear stress (i.e., mean value of $283 \mathrm{~Pa}$ ). Similar results can be observed for clayey soils [32]. Viscosity is also dependent on the shear rate and time. At low shear rates, the final viscosity rapidly decreases with an increasing shear rate; however, there is no significant variation after an initial shear rate of $0.1 \mathrm{~s}^{-1}$. In particular, there is a pseudo-Newtonian viscosity (not shown, but slopes may be found) in the elastic domain before the static yield stress for three higher shear rates. Interestingly, the pseudo-Newtonian viscosity increases with an increasing shear rate (Figure 4a). Compared to the Bingham yield stress and viscosity of the sand-rich materials tested, the yield stress and viscosity obtained from stress growth tests are approximately 35-45 times and 100-35,000 times higher, respectively, than those obtained from flow curve tests (Figure 4). Similar results have been observed for other thixotropic materials. According to previous studies $[6,11,13]$, the difference between static and dynamic yield stresses ranges between 1.5 and 2-fold. It is, of course, believed that the difference is larger when the solid volume concentration is greater.
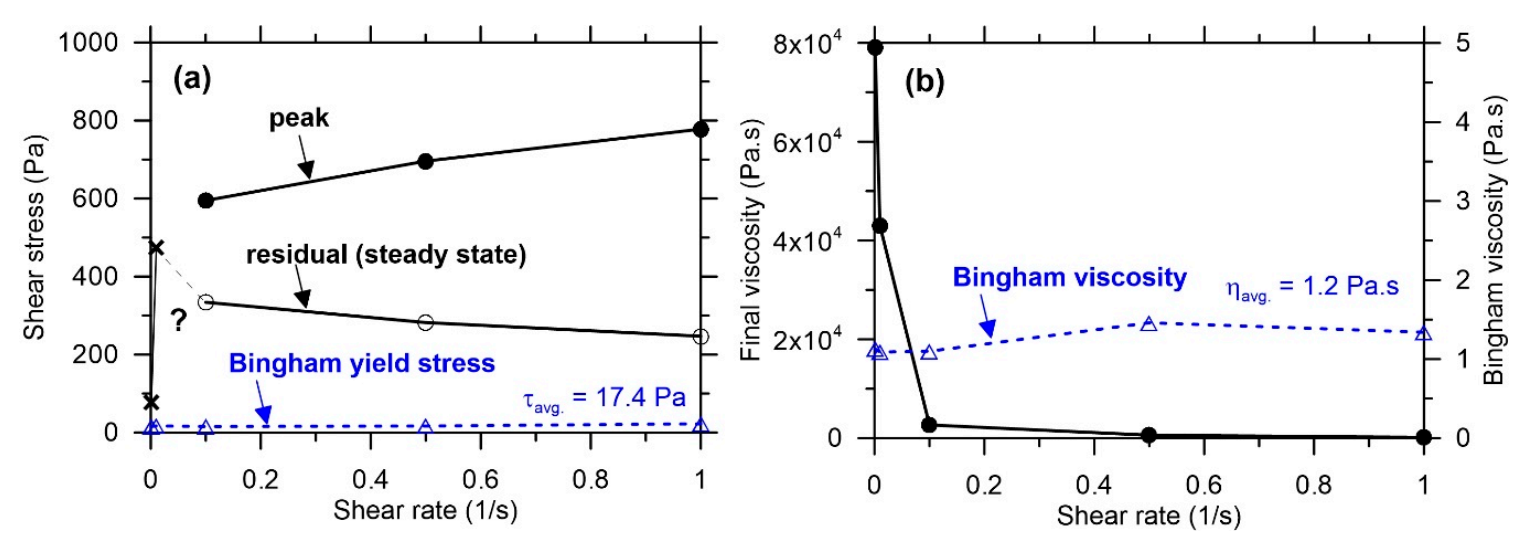

Figure 5. Static and dynamic rheological properties of sand-rich mine tailings: (a) Peak, residual shear stress, and the Bingham yield stresses; (b) final viscosity and the Bingham viscosity.

\subsection{Rheological Properties and Possible Implications for Debris Flow Modeling}

The rheological parameters are essential for examining debris flow propagation and designing measures for future catastrophic events. For many cases in debris flow simulation, the value of the yield stress is fixed during the flow as a first approximation to understand post-failure characteristics. In this case, the determination of yield stress is crucial. Engineers could obtain the shear strength from field vane tests under in situ conditions and fall cone tests in the laboratory as a priority, which would be more reliable for debris flow initiation. For fine-grained sediments, the yield stress obtained from the material, which is assumed to behave as a Bingham fluid, is very close to the undrained shear strength determined by fall cone tests. For a given sand-rich material, the Bingham yield stress and undrained shear strength were compared for a given solid volume concentration ranging from $50 \%$ to $65 \%$. Figure 6 presents a comparison of the shear strength measured from the Bingham yield stress in flow curve tests, the static yield stress in time-dependent tests, and the undrained shear strength in fall cone tests. A simple relationship can be expressed as $C_{v s}=74 \cdot S_{u}{ }^{0.1}(\mathrm{kPa})$. For $\mathrm{C}_{\mathrm{vs}}=50 \%$, the Bingham yield stress and undrained shear strength range between 0.02 and $0.06 \mathrm{kPa}$ (mean value of $40 \mathrm{~Pa}$ ); 
however, the static yield stress is approximately $0.6-0.9 \mathrm{kPa}$ (mean value of $700 \mathrm{~Pa}$ ). The difference is more than 10-fold. More interestingly, as described above, the sediments are much more resistant to flow when the shear rate is increased. These results suggest that more research is needed to understand the mechanism related to the high mobilization of debris flows, e.g., entrainment, hydroplaning, yield stress reduction, and wetting processes in debris flow motion. It is necessary to revisit the research work ([24] see Figure 8 in the paper) on failure and post-failure characteristics of mine deposit areas and to estimate the debris flow mobility for such areas. Using the same geometry for the initial slope and volume with different yield stresses, the debris flow propagation can be simply compared. For a given yield stress of $50 \mathrm{~Pa}$, the runout distance is approximately $700 \mathrm{~m}$, but for a stress of $700 \mathrm{~Pa}$, the distance is approximately $100 \mathrm{~m}$. The difference is more than 7 -fold. The debris flow velocity is more sensitive to the variation in yield stress. The difference is more than 10 -fold. This result means that the debris flow impact can be determined by determining the yield stress. In this context, more precise computational techniques based on rheological studies are required to avoid overdesigning for future disasters and to establish reasonable measures.

It is very difficult to describe debris flow with one fixed rheological model, because it is expected that the flow behaviors of real debris flow are too complex. In particular, the influence of material parameters (such as the particle size distribution, change in water content, porosity, roughness, edge and wall slip effects) in estimating the flow mobility should be scrutinized in future work. Even with a very simplified hypothesis in which many parameters, such as the particle size distribution, water content, porosity, roughness, solid concentration, and topographic characteristics are simplified with ordinary constants, the research findings presented in this study can be simply applied to debris flow mitigation in mine tailing. In addition, micro-structural evolution of the particles in terms of landslide mobilization has a substantial contribution in the destructuration-restructuration process [33].

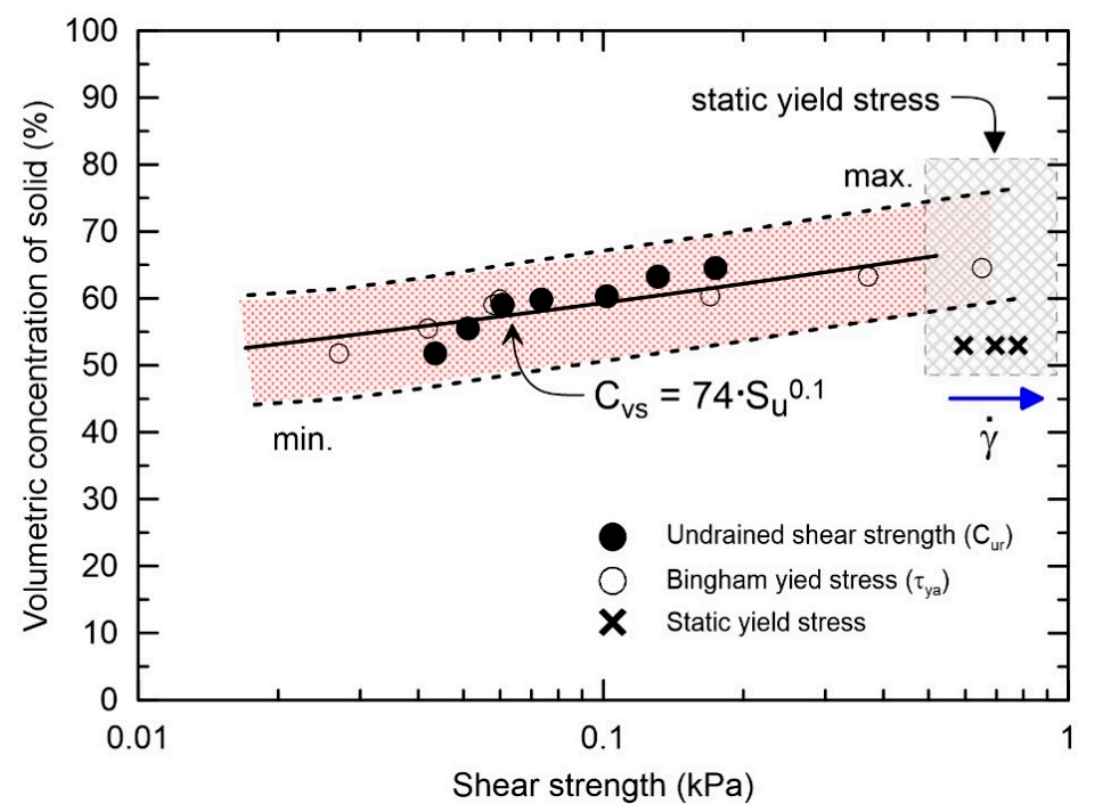

Figure 6. Relationship between the shear strength and the solid volume concentration.

\section{Conclusions}

The dynamic and static yield stresses of mine tailings, which are exposed on natural slopes in abandoned mine deposits and potentially vulnerable to future geochemical and geophysical modification, have been identified and examined in this study. The rheological properties, the yield stresses and viscosity, have been determined using the ball-measuring system, which is a well-known piece of apparatus suitable for large particles. The yield stresses obtained from the flow curve and stress growth methods have been compared. In the plot of shear stress and the shear rate (flow 
curve), there is a peak value related to the generation of the slip surface due to the high percentage of soils; after the critical shear rate, the materials behave as Bingham fluids. The shear resistance before yielding is different from the applied initial shear rates. The pseudo-Newtonian viscosity increases with decreasing initial shear rates. However, the Bingham yield stress and viscosity are obtained within a similar range, regardless of the initial shear rates applied. Therefore, the Bingham rheology is applicable as a first approximation for debris flow motion to examine the post-failure characteristics of mass movement. These results can be used from a very conservative point of view. The yield stress can be obtained from the stress growth tests (the measurement of shear stress with a constant shear rate). In this case, it is called the static yield stress. The static yield stresses are strongly affected by the shear rate. At relatively low shear rates, the flow curve seems to demonstrate Newtonian behavior for a given period of time. However, after a certain amount of time, the flow curve displays strain-softening behavior similar to that in soil mechanics. A large difference is found between the dynamic and static yield stresses. The largest difference is approximately 45 -fold. In general, the static yield stress is related to the flow starting, but the dynamic yield stress is related to the flow stopping. This effect may result in an underestimation of the debris flow mobility if only the static yield stress and residual shear stress from the stress growth test are considered. In landslide dynamics, at the onset of slope failure, the undrained shear strength and static yield stress may be useful for examining the generation of slip surfaces; however, at the transition to flow conditions, the transition from the static yield stress to the Bingham yield stress should be considered. Yield stress reduction must be taken into account in highly mobile debris flow hazards, which are related to hydroplaning, particle migration, and wetting effects during flow.

Funding: This research was supported by the KIGAM Research project (19-3413).

Acknowledgments: The author also extends special thanks to the anonymous reviewers and editor for their valuable comments and recommendations for publishing this paper.

Conflicts of Interest: The author declares no conflicts of interest.

\section{References}

1. Barnes, H.A. The yield stress-A review or ' $\pi \alpha v \tau \alpha \rho \varepsilon \iota^{\prime}-$ Everything flows? J. Non-Newton. Fluid Mech. 1999, 81, 133-178. [CrossRef]

2. Coussot, P.; Nguyen, Q.D.; Huynh, H.T.; Bonn, D. Viscosity bifurcation in thixotropic, yielding fluids. J. Rheol. 2002, 46, 573-589. [CrossRef]

3. Moller, P.C.F.; Mewis, J.; Bonn, D. Yield stress and thixotropy: On the difficulty of measuring yield stresses in practice. Soft Matt. 2006, 2, 274-283. [CrossRef]

4. Mewis, J.; Wagner, N.J. Thixotropy. Adv. Colloid Interface Sci. 2009, 147-148, 214-227.

5. Qian, Y.; Kawashima, S. Use of creep recovery protocol to measure static yield stress and structural rebuilding of fresh cement pastes. Cem. Concr. Res. 2016, 90, 73-79. [CrossRef]

6. Qian, Y.; Kawashima, S. Distinguishing dynamic and static yield stress of fresh cement mortars through thixotropy. Cem. Concr. Comp. 2018, 86, 288-296. [CrossRef]

7. Nguyen, Q.D.; Boger, D.V. Measuring the Flow Properties of Yield Stress Fluids. Annu. Rev. Fluid Mech. 1992, 24, 47-88. [CrossRef]

8. Stokes, J.R.; Telford, J.H. Measuring the yield behaviour of structured fluids. J. Non-Newton. Fluid Mech. 2004, 124, 137-146. [CrossRef]

9. Mewis, J. Thixotropy-A general review. J. Non-Newton. Fluid Mech. 1979, 6, 1-20. [CrossRef]

10. Barnes, H.A. Thixotropy—A review. J. Non-Newton. Fluid Mech. 1997, 70, 1-33. [CrossRef]

11. Moller, P.; Fall, A.; Chikkadi, V.; Derks, D.; Bonn, D. An attempt to categorize yield stress fluid behaviour. Philos. Trans. R. Soc. A Math. Phys. Eng. Sci. 2009, 367, 5139-5155. [CrossRef] [PubMed]

12. Cheng, D.C.H. Yield stress: A time-dependent property and how to measure it. Rheol. Acta 1986, 25, 542-554. [CrossRef]

13. Santolo, A.S.D.; Pellegrino, A.M.; Evangelista, A.; Coussot, P. Rheological behaviour of reconstituted pyroclastic debris flow. Géotechnique 2012, 62, 19-27. [CrossRef] 
14. Barnes, H.A.; Walters, K. The yield stress myths? Rheol. Acta 1985, 24, 323-326. [CrossRef]

15. Astarita, G. Letter to the editor: The engineering reality of the yield stress. J. Rheol. 1990, 34, $275-277$. [CrossRef]

16. De Souza Mendes, P.R. Modeling the thixotropic behavior of structured fluids. J. Non-Newton. Fluid Mech. 2009, 164, 66-75. [CrossRef]

17. O'Brien, J.S.; Julien, P.Y. Laboratory Analysis of Mudflow Properties. J. Hydraul. Eng. 1988, 114, $877-887$. [CrossRef]

18. Coussot, P.; Piau, J.M. On the behavior of fine mud suspensions. Rheol. Acta 1994, 33, 175-184. [CrossRef]

19. Schatzmann, M.; Bezzola, G.R.; Minor, H.E.; Windhab, E.J.; Fischer, P. Rheometry for large-particulated fluids: Analysis of the ball measuring system and comparison to debris flow rheometry. Rheol. Acta 2009, 48, 715-733. [CrossRef]

20. Sosio, R.; Crosta, G.B. Rheology of concentrated granular suspensions and possible implications for debris flow modeling. Water Resour. Res. 2009, 45, W03412. [CrossRef]

21. Campbell, C.S. Rapid Granular Flows. Annu. Rev. Fluid Mech. 1990, 22, 57-90. [CrossRef]

22. Jeong, S.W.; Wu, Y.H.; Cho, Y.C.; Ji, S.W. Flow behavior and mobility of contaminated waste rock materials in the abandoned Imgi mine in Korea. Geomorphology 2018, 301, 79-91. [CrossRef]

23. Imran, J.; Parker, G.; Locat, J.; Lee, H. 1D Numerical Model of Muddy Subaqueous and Subaerial Debris Flows. J. Hydraul. Eng. 2001, 127, 959-968. [CrossRef]

24. Jeong, S.W. Geotechnical and rheological characteristics of waste rock deposits influencing potential debris flow occurrence at the abandoned Imgi Mine, Korea. Environ. Earth Sci. 2015, 73, 8299-8310. [CrossRef]

25. Bisantino, T.; Fischer, P.; Gentile, F. Rheological characteristics of debris-flow material in South-Gargano watersheds. Nat. Hazards 2010, 54, 209-223. [CrossRef]

26. Kaitna, R.; Rickenmann, D.; Schatzmann, M. Experimental study on rheologic behaviour of debris flow material. Acta Geotech. 2007, 2, 71-85. [CrossRef]

27. Jeong, S.W.; Locat, J.; Leroueil, S.; Malet, J.-P. Rheological properties of fine-grained sediment: The roles of texture and mineralogy. Can. Geotech. J. 2010, 47, 1085-1100. [CrossRef]

28. Locat, J.; Demers, D. Viscosity, yield stress, remolded strength, and liquidity index relationships for sensitive clays. Can. Geotech. J. 1988, 25, 799-806. [CrossRef]

29. Bingham, E.C. Fluidity and Plasticity; McGraw Hill: New York, NY, USA, 1922; p. 440.

30. Coussot, P.; Tocquer, L.; Lanos, C.; Ovarlez, G. Macroscopic vs. local rheology of yield stress fluids. J. Non-Newton. Fluid Mech. 2009, 158, 85-90. [CrossRef]

31. Germann, N. Shear banding in semidilute entangled polymer solutions. Curr. Opin. Colloid Interface Sci. 2019, 39, 1-10. [CrossRef]

32. Tika, T.E.; Vaughan, P.R.; Lemos, L.J.L.J. Fast shearing of pre-existing shear zones in soil. Géotechnique 1996, 46, 197-233. [CrossRef]

33. Huynh, H.T.; Roussel, N.; Coussot, P. Aging and free surface flow of a thixotropic fluid. Phys. Fluids 2005, 17, 033101. [CrossRef]

(C) 2019 by the author. Licensee MDPI, Basel, Switzerland. This article is an open access article distributed under the terms and conditions of the Creative Commons Attribution (CC BY) license (http://creativecommons.org/licenses/by/4.0/). 